\title{
A VIAGEM DE JUST-JEAN-ÉTIENNE ROY (ARMAND DE B***) AO OESTE DO RIO GRANDE DO SUL. 2 - NOTAS COMPLEMENTARES E ANÁLISE CRÍTICA ${ }^{1}$
}

\author{
JOSÉ NEWTON CARDOSO MARCHIORI ${ }^{2}$
}

\section{RESUMO}

Demonstra-se que o texto de Just-Jean-Étienne Roy não constitui um autêntico relato de viagem, pelas numerosas descrições extraídas do livro de Arsène Isabelle.

Palavras-chave: Aimé Bonpland, Armand de B***, Arsène Isabelle, Just-Jean-Étienne Roy, Rio Grande do Sul, São Borja, Viajantes.

\section{ABSTRACT}

[The travel of Just-Jean-Étienne Roy (Armand de B***) to the west of Rio Grande do Sul State (Brazil). 2 - Additional notes and critical analysis of the work].

It is demonstrated that the text of Just-Jean-Étienne Roy is not a true account of a journey, due repeating descriptions from the book of Arsène Isabelle.

Keywords: Aimé Bonpland, Armand de B***, Arsène Isabelle, Brazil, Just-Jean-Étienne Roy, Municipality of San Borja, Rio Grande do Sul State, Travel Literature.

\section{INTRODUÇÃO}

Na recente publicação em português dos fragmentos da obra de Just-Jean-Étienne Roy relativos ao oeste do Rio Grande do $\mathrm{Sul}^{3}$, três aspectos pendentes foram salientados pelos tradutores: a utilização de um pseudônimo por parte do autor (Armand de B***), em contraste com o restante de sua bibliografia; as escassas referências pessoais a Aimé Bonpland, objetivo principal da viagem; e a inconsistência das descrições de lugares visitados, inclusive de São Borja. Embora intimamente ligado aos itens precedentes, um quarto aspecto poderia ser lembrado em reforço ao questionamento da efetiva realização da viagem: a indefinição do autor sobre a data, ponto que, embora sem maior

1 Recebido em 10-7-2014 e aceito para publicação em 25-7-2014.

2 Professor Titular, Dr., Departamento de Ciências Florestais, Universidade Federal de Santa Maria. Bolsista de Produtividade em Pesquisa (CNPq-Brasil). marchiori@pq.cnpq.br

3 MARCHIORI NETO, D.L.; MARCHIORI, J.N.C. A viagem de Just-Jean-Étienne Roy (Armand de B***) ao oeste do Rio Grande do Sul. 1 - Visita a Aimé Bonpland na vila de São Borja. Balduinia, Santa Maria, n. 45, p. 17-32, 2014 . embasamento, recebeu considerações pouco divergentes entre os pesquisadores que opinaram sobre o texto.

O presente artigo visa a analisar mais detidamente os fragmentos traduzidos ao português em artigo precedente, e demonstrar que as descrições de Just-Jean-Étienne Roy não compõem um autêntico relato de viagem, pela apropriação do texto de Arsène Isabelle.

\section{ANÁLISE CRÍTICA E NOTAS}

Ao comentar a obra em foco, Abeillard Barreto, o maior conhecedor da bibliografia sulrio-grandense, ponderou que a viagem de Roy foi realizada "mais ou menos em 1842", destacando que a vila de São Borja, "recorrida em companhia do sábio francês", foi descrita com "enorme simpatia". ${ }^{4}$ Sobre o mesmo ponto, Stephen Bell foi menos preciso ${ }^{5}$, posicionando

\footnotetext{
4 BARRETO, A. Bibliografia sul-riograndense. Rio de Janeiro: Conselho Federal de Cultura, 1976. v. 2. p. 1.165 .

5 "One French travel account, the work of the pseudonymous Armand de B. (Jean-Just-Étienne Roy), traveling with a Dr. Philips, was structured entirely around a visit made in the 1840s from de the mouth of the Plata ascending the Uruguay River to Bonpland's
} 
a viagem nos anos de 1840 . Não custa comentar, por fim, que o autor e a obra nem sequer são mencionados por outros especialistas em bibliografia sul-rio-grandense, tais como Villas-Bôas (1974) e Martins (1978).

As datas aventadas no parágrafo anterior baseiam-se tanto em fatos relatados como - e principalmente - em flagrantes omissões que permeiam o texto. Entre outros, este é o caso da ausência de menções a Uruguaiana e a Restauración (atual Paso de los Libres), visto que a única localidade citada na viagem fluvial entre Bella Unión (Uruguai) e Itaqui foi o "povoado de Santa Anna". Por si só, esta lacuna permite datar a viagem como anterior a 1843 , pois foi no início desse ano que se deu o povoamento da sede da moderna cidade brasileira ${ }^{6}$, o mesmo acontecendo com a argentina Restauración, fundada no outro lado do rio Uruguai pelo General Joaquin Madariaga, em 12 de setembro de 1843. Se essas localidades já existissem, elas certamente não passariam em branco no texto de Roy, que prima pela escassez de registros.

Na visita à vila de São Borja, ao referir a atribuição de Bonpland pelo mau estado de conservação da igreja e demais prédios remanescentes da redução jesuítica a eventos como a Revolução Farroupilha ${ }^{7}$, o autor parece apontar para a segunda metade da década de 1840 , período ainda condizente à indicação do pesquisador americano, mas não com o ano fixado

home at São Borja" (BELL, S. A life in shadow. Aimé Bonpland in Southern South America, 1817-1858. Stanford: Stanford University Press, 2010. p. 158).

6 Sob a invocação de Santa Ana, o início do povoamento da sede deu-se em 1843, após o esvaziamento do extinto povoado de Santa Ana, citado no texto em análise, em decorrência de frequientes inundações. A criação da primeira capela no sítio urbano da atual Uruguaiana foi definida pelo Decreto da República Rio-Grandense $\mathrm{n}^{\circ} 21$, de 24 de fevereiro de 1843 (FORTES, A.B.; WAGNER, J.B.S. História administrativa, judiciária e eclesiástica do Rio Grande do Sul. Porto Alegre: Editora Globo, 1963. p. 449).

7 "et les désastres plus récents, mais non plus déplorables de la guerre civile, dans cette partie du Brésil, apaisée seulement depuis bien peu de temps" (p. 173). por Abeillard Barreto, visto que o conflito terminou apenas em 1845.

$\mathrm{O}$ texto padece de inconsistências de toda a ordem, se examinado a fundo. As referências feitas a São Borja, à pessoa de Aimé Bonpland, bem como à sua casa na vila são demasiado pobres para justificar a travessia do oceano Atlântico e os investimentos implícitos em tal viagem: essa é a nítida impressão que se tem ao ler os fragmentos em análise. Quase todo o texto versa sobre a atividade missionária dos jesuítas, a estrutura por eles implantada nas reduções, e a personalidade refratária dos índios à dita "civilização", temas amplamente encontrados na literatura dos séculos dezoito e dezenove.

Além disso, o esforço em imprimir "cor local" ao relato transparece em vários momentos. Recurso próprio de ficcionistas, esse traço demonstra trabalho de pesquisa, mas não esconde a real intenção do autor se usado de forma inadequada. Muito ilustrativa é a referência ao vento "pampero", ao descrever o temor causado pelo péssimo estado de conservação da igreja jesuítica de São Borja:

Nous hésitâmes quelque temps à visiter l'intérieur de l'ancienne église. Chaque fois qu'il fait un vent un peu violent, comme le pampero, il se détache du toit d'enormes poutres, qui, roulant avec fracas, ébranlent le reste du vieil édifice. ${ }^{8}$

Em vez de reforço literário, a citação do autor resulta postiça, visto que o pampeiro não é uma simples rufada ou "golpe de vento". O que mais transparece na referência do autor é a (vã) tentativa de legitimar a experiência como fato vivenciado, corroborando outros indícios, analisados mais adiante.

\footnotetext{
8 "Nós hesitamos por algum tempo até visitar o interior da antiga igreja, porque parecia em vias de ruir a qualquer momento. Cada vez que soprava um vento mais violento, como o pampero, se destacava do teto enormes vigas que, oscilando ruidosamente, sacudiam o resto do velho edifício" (MARCHIORI NETO \& MARCHIORI, 2014. Op. cit., p. 26).
} 
Não menos estranheza causa a referida insistência do velho Bonpland em acompanhar os viajantes até o embarcadouro de Itapua, no rio Paraná, pelo simples motivo de "prolongar o prazer" de conversar "francês com franceses". 9 Distante 140km de São Borja, em linha reta, o percurso é demasiado longo, cansativo e prolongado para ser feito a cavalo, ida e volta, sem real necessidade. Só mesmo quem não conhecia a vida atribulada e cheia de compromissos materiais de Bonpland poderia achar plausível tamanha gentileza.

Não é necessário esgotar os elementos de suspeição constantes no "relato de viagem": a obra soa falsa a todo o momento, recomendando a investigação da "fonte original".

A pesquisa em textos de cronistas do século dezenove não tarda a encontrar a verdadeira mina: a "viagem" de Just-Jean-Étienne Roy a São Borja - e a consequente visita a Bonpland -, não passam de mero plágio da obra de Arsène Isabelle, cuja edição princeps data de 1835 , e relata o percurso fluvial desse aventureiro francês, iniciado em Buenos Aires no dia 25 de setembro de 1833.

Ao dispor, lado a lado, alguns fragmentos extraídos dos livros de Arsène Isabelle e JustJean-Étienne Roy, o Quadro 1 esclarece, definitivamente, a questão. Resta informar que os fragmentos da obra de Isabelle procedem da edição brasileira de 1949, traduzida ao português pelo poeta modernista e embaixador gaúcho Teodomiro Tostes ${ }^{10}$; os de Just-Jean-Étienne Roy, devem-se à tradução de Marchiori Neto \& Marchiori, e foram publicados na edição anterior $^{11}$ de Balduinia.

QUADRO 1 - Fragmentos das obras de Arsène Isabelle e Just-Jean-Étienne Roy, relativos ao percurso de Bella Unión (Uruguai) a São Borja, bem como a essa vila.

Não havia mais do que quarenta ranchos em pé, mas parece que existiam duzentos em 1832, e que esse ponto era mais povoado e mais comercial do que Salto. Funcionavam ali uma agência da alfândega, um comando do porto e um comando militar, encarregado da polícia. Era a última povoação da Banda Oriental antes das Missões Brasileiras, cuja fronteira estava apenas a duas léguas (p. 216)
Nesta última não havia mais do que quarenta ranchos, sendo que havia mais de duzentos em 1832, o que então tornava a localidade mais povoada e comercial do que Salto, dispondo de aduana, de um comandante do porto, e de um comandante militar encarregado da polícia. Foi o último povoado da Banda Oriental em direção às Missões Brasileiras, cuja fronteira fica a apenas oito quilômetros de distância (p. 21)

Este lugar dista $160 \mathrm{~km}$ de Salto, pelo rio (p. 21).

Desse lugar a Salto, contam-se quarenta léguas, pelo rio (p. 216)

Não tardamos a atingir a terra brasileira e notamos com satisfação uma enorme diferença no aspecto Não tardamos a chegar a terras brasileiras (província do Rio Grande do Sul ou de São Pedro), e percebemos, com satisfação, uma diferença notável

${ }^{10}$ ISABELLE, A. Viagem ao Rio da Prata e ao Rio Grande do Sul. Rio de Janeiro: Zélio Valverde, 1949. 345 p.

${ }^{11}$ MARCHIORI NETO, D.L.; MARCHIORI, J.N.C. A viagem de Just-Jean-Étienne Roy (Armand de B***) ao oeste do Rio Grande do Sul. 1 - Visita a Aimé Bonpland na vila de São Borja. Balduinia, Santa Maria, n. 45, p. 17-32. 2014
9 MARCHIORI NETO \& MARCHIORI, 2014. Op. cit., p. 31). 
uma aparência de vida e de cultura que contrastava, singularmente, com os desertos que acabávamos de percorrer. Os brasileiros não são mais industriosos nem mais trabalhadores do que os orientais e os argentinos; mas as estâncias se multiplicaram muito nessas regiões durante e depois da guerra de ocupação (p. 216-217) no aspecto do país: campos verdes, árvores no campo, muitos rebanhos nas encostas de coxilhas ou nas planícies; veados e avestruzes em abundância, enfim, um aspecto de vida e de cultura que contrastava nitidamente com os desertos que acabáramos de percorrer. Os brasileiros não são mais diligentes ou trabalhadores do que seus vizinhos orientais e argentinos; mas as estâncias se multiplicaram muito nestes países, durante e depois da guerra (p. 21)

Há ali também o cuidado de queimar frequentemente o campo, processo que renova o pasto e contribui muito para a fertilidade da terra, devido aos sais contidos nas cinzas e à destruição dos animais prejudiciais, como, por exemplo, os reptis (sic), os gafanhotos e as formigas, que pululam em toda a parte nos tempos de calor (p. 217)

Passamos a noite de 9 na ourela de um bosque à margem do Arroyo del Tigre. Juntaram-se a nós quatro brasileiros armados, que seguiam, numa piroga feita de um tronco de árvore, para um lugar pouco distante dali. Ofereceram-nos, amavelmente, um pedaço de carne fresca, que nos veio em boa hora, porque o nosso charque, embrulhado num couro antes de estar bem seco, e exposto depois às chuvas contínuas, começava a corromper-se. Salvo alguns pombos, quero-queros e um veado que conseguimos caçar, só comíamos, ordinariamente, essa carne má e muito salgada, acompanhada da farinha de mandioca que fazia as vezes de pão (p. 217)

Disseram-nos que nada tínhamos a temer na terra brasileira, nem dos animais nem dos homens, ao contrário do que acontecia no país que tínhamos percorrido. Citaram-nos muitas pilhagens, cometidas havia pouco tempo, e nos garantiram que tínhamos tido muita sorte em escapar do ataque dos índios errantes, que rondam as margens do Uruguai para assaltar os viajantes (p. 217).

A 14, passamos diante da aldeia de Santana, primeira guarnição brasileira ao subir o Uruguai (p. 215)
Por vezes também se preocupam de queimar os campos, prática que renova a grama e contribui significativamente para a fertilidade, devido aos sais contidos nas cinzas, além de destruir pragas, como répteis, gafanhotos e formigas, que pululam por todos os lugares durante o calor (p. 21)

Nós acampamos pela primeira vez em terras brasileiras à margem da mata ciliar do Arroyo del Tigre. Juntaram-se a nós quatro brasileiros armados que vieram em uma longa canoa feita de um único tronco de árvore. Eles nos deram, de boa vontade, um pedaço de carne fresca, produto de que nós embalado em couro antes de ser seco, começou a estragar devido às chuvas incessantes e, salvo alguns pombos, quero-queros (teruteros) e um veado, quando se podia pegar, comíamos a carne ruim, como regra, muito salgada, torrada ou moída, com farinha de mandioca em lugar de pão (p. 21-22)

Eles se apressaram a dizer que não tínhamos nada a temer em terra brasileira, nem de animais, nem de homens, mas que não era assim no país de onde tínhamos vindo. Contaram-nos vários atos de banditismo que tinham acontecido recentemente, e afirmaram que nós tivemos muita sorte por não que rondam as bordas do Uruguai para saquear viajantes (p. 22)

No mesmo dia, passamos pelo povoado de Santa Anna, a primeira guarda brasileira ao se remontar o rio Uruguai (p. 22) muito precisávamos, uma vez que o nosso charque, termos sido atacados por índios ou gaúchos errantes 
A 18 de Novembro, no momento em que admirávamos um belo nascer do sol, o patrão nos disse, mostrando ao longe uma palmeira muito elevada, a única que conseguimos ver na margem oriental: "Estão chegando ao fim de seus trabalhos. Ali está a estância de São Marcos, que dista, apenas, umas dez léguas da vida (sic) de Itaqui” (p. 220).

O estancieiro brasileiro ofereceu-nos um jantar esplêndido, acompanhado de um excelente vinho do Porto (p. 221)

Lucramos também com a troca pela "Chalana", barco chato, coberto por um tecto feito de caniços e de couros esticados por meio de correias (p. 222).

São Borja (a povoação) está situada a mais de uma légua do porto. Encontram-se, depois de atravessar o mato da margem esquerda por caminhos tortuosos e enlameados, alguns ranchos os do Porto, como são chamados (p. 223)

Os habitantes, acostumados como os argentinos e orientais a não darem um passo a pé, nos olhavam muito admirados (p. 224).

Em breve, a torre quadrada da igreja se ofereceu ao nosso olhar. À medida que subíamos, íamos descobrindo, diante de nós, bosques, laranjais, chácaras cercadas de fossos enfeitados de bromélias de folhas cor de sangue e belas flores em espiga, e, longe, no leste, bosques de pouca extensão, espaçados como quintas da Alta Normandia (p. 224).

No lado norte da praça, estava situada a igreja (...) (p. 226).

Hesitamos algum tempo, antes de visitarmos a igreja, porque temíamos que seu teto desabasse de um momento para outro. Cada vez que o vento sopra, desprendem-se do teto enormes vigas, que, rolando com estrondo, sacodem o resto do antigo edifício, cuja forma é um quadrado longo (p. 227).
Quatro dias mais tarde, ao admirar um belo nascer do sol, o nosso chefe nos disse, mostrando-nos ao longe uma palmeira muito alta: chegou o fim de seus problemas; aqui é a estância de São Marcos, distante apenas quarenta quilômetros da vila de Itaqui (p. 14).

O estancieiro brasileiro recebeu-nos muito bem e nos deu uma excelente refeição, regada com bom vinho do Porto (p. 22).

Nós ganhamos na mudança, porque a nossa nova chalana era coberta de um teto leve, feito de juncos e couros, presos por correias (p. 22).

São Borja (a vila ou cidade) situa-se a mais de quatro quilômetros do porto. Depois de havermos passado pela floresta da margem esquerda por caminhos tortuosos e lamacentos, encontramos os ranchos do porto (p. 23).

Os habitantes se surpreendiam muito, pois não estavam acostumados, como os argentinos e orientais, a dar um único passo a pé (p. 23).

Logo a torre quadrada da igreja se oferecia aos nossos olhos. Enquanto subíamos, encontramos, à nossa frente, bosques, pomares e chácaras cercadas por fossos cheios de bromélias de folhas vermelhas como sangue e belas flores em espigas. Ao longe, víamos bosques de pequena extensão, espaçados como as fazendas da Alta-Normandia (p. 23)

Sobre o lado norte da praça se encontra a igreja (...) (p. 25).

Nós hesitamos por algum tempo até visitar o interior da antiga igreja, porque parecia em vias de ruir a qualquer momento. Toda vez que soprava um vento mais violento, como o pampero, se destacavam do teto enormes vigas que, oscilando ruidosamente, sacudiam o resto do velho edifício. A forma desse edifício é um quadrado longo (p. 26). 
Baseado no texto de Isabelle, e com longas citações de um artigo de Alfred Demersay sobre "a vida e os trabalhos de Aimé Bonpland", publicado em 1853 no Bulletin da la Societé de Géographiee ${ }^{12}$, quase nada resta de autoral na obra em análise, a qual é marcada, além disso, pela ausência do típico "frescor" de um relato de viagem.

A respeito de Alfred Demersay, cumpre informar que ele veio à América do Sul em 1844, em missão oficial, com vistas às tratativas para o reatamento de ligações com o novo Paraguai que surgia após a morte de Francia ${ }^{13}$, ditador que aprisionara Bonpland por quase dez anos em seu território. Na ida para Assunção, Demersay atravessou o Rio Grande do Sul a fim de se encontrar com o botânico francês em São Borja, oportunidade que lhe permitiu conhecer, pessoalmente, as antigas reduções jesuíticas da margem oriental do rio Uruguai, sobre as quais fornece material iconográfico de valor inestimável. É o caso, entre outras, das "Ruínas de São Miguel" (Figura 1) e, de maior interesse para o presente artigo, da "casa de Bonpland em São Borja" (Figura 2). Sobre esta última, volta-se a falar mais adiante.

Cabe salientar, todavia, que a obra-prima de Demersay começou a ser publicada no mesmo ano da "viagem" de Jean-Just-Étienne Roy ${ }^{14}$, explicando a ausência das preciosas ilustrações fornecidas pelo culto médico francês. Roy nem mesmo apresenta um retrato de Bonpland, lacuna que se mostra de difícil compreensão, uma

${ }^{12}$ DEMERSAY, A. Notice sur la vie et les travaux de M. Aimé Bonpland. Bulletin de la Societé de Géographie, Paris, v. 5, p. 240-254, 1853.

${ }^{13}$ José Gaspar Rodríguez de Francia (1776-1840). Doutor em Teologia (Universidad de Córdoba, Argentina), revolucionário e político paraguaio, nomeado "Ditador Perpétuo da República do Paraguai” a partir de 1816. Outro cognome associado ao ditador é o de "El Supremo", título dado à obra biográfica escrita pelo eminente intelectual e historiador paraguaio Augusto Roa Bastos (1917-2005).

${ }^{14}$ DEMERSAY, A. Histoire physique, économique et politique du Paraguay et des établissements des jésuites. Paris: L. Hachette et Cie., 1860-1865. vez que o próprio autor informa, textualmente, haver recebido uma fotografia do botânico francês em Salto ${ }^{15}$, por gentileza de um certo Sr. Thedy, personalidade, aliás, que mereceu longas referências na obra de Isabelle ${ }^{16}$, distintamente de Roy. A única ilustração da obra em análise, reproduzida na Figura 3, retrata a caça à avestruz com boleadeiras, por um índio charrua montado a cavalo.

Com relação ao flagrante plágio do texto de Arsène Isabelle, demonstrado no Quadro 1, outros pontos ainda requerem comentário.

As pequenas diferenças de texto podem ser debitadas tanto à reescritura ou adaptação do texto de Isabelle, realizada por Roy, como à tradução dos originais franceses, realizada por autores distintos e em tempos muito afastados entre si.

As distâncias geográficas, expressas em léguas por Isabelle, correspondem aos quilômetros de Roy, divididos por quatro: entre Bella Unión e a fronteira do Rio Grande do Sul foram referidas 2 léguas por Isabelle e $8 \mathrm{~km}$ por Roy; de Bella Unión a Salto, 40 léguas e 160 km; da "estância de São Marcos" a Itaqui, 10 léguas e 40km; e do "passo" à vila de São Borja, "mais de uma légua" e "mais de 4 quilômetros", respectivamente.

Ainda sobre o Quadro 1, vê-se que Isabelle menciona o dia do mês nas referências a localidades, ao passo que Roy menciona o tempo correspondente, gasto no percurso entre as mesmas. Isabelle, por exemplo, relata haver passado "diante da aldeia de Santana" no dia 14 de Novembro e chegado à estância de São Marcos ao "nascer do sol" de 18 de Novembro; mais econômico - e sempre impreciso -, como convém, aliás, aos que desconhecem um tema a

\footnotetext{
${ }^{15}$ MARCHIORI NETO, D.L.; MARCHIORI, J.N.C. A viagem de Just-Jean-Étienne Roy (Armand de B***) ao oeste do Rio Grande do Sul. 1 - Visita a Aimé Bonpland na vila de São Borja. Balduinia, Santa Maria, n. 45, 2014, p. 23.

${ }^{16}$ ISABELLE, 1949. Op. cit., p. 203-204.
} 


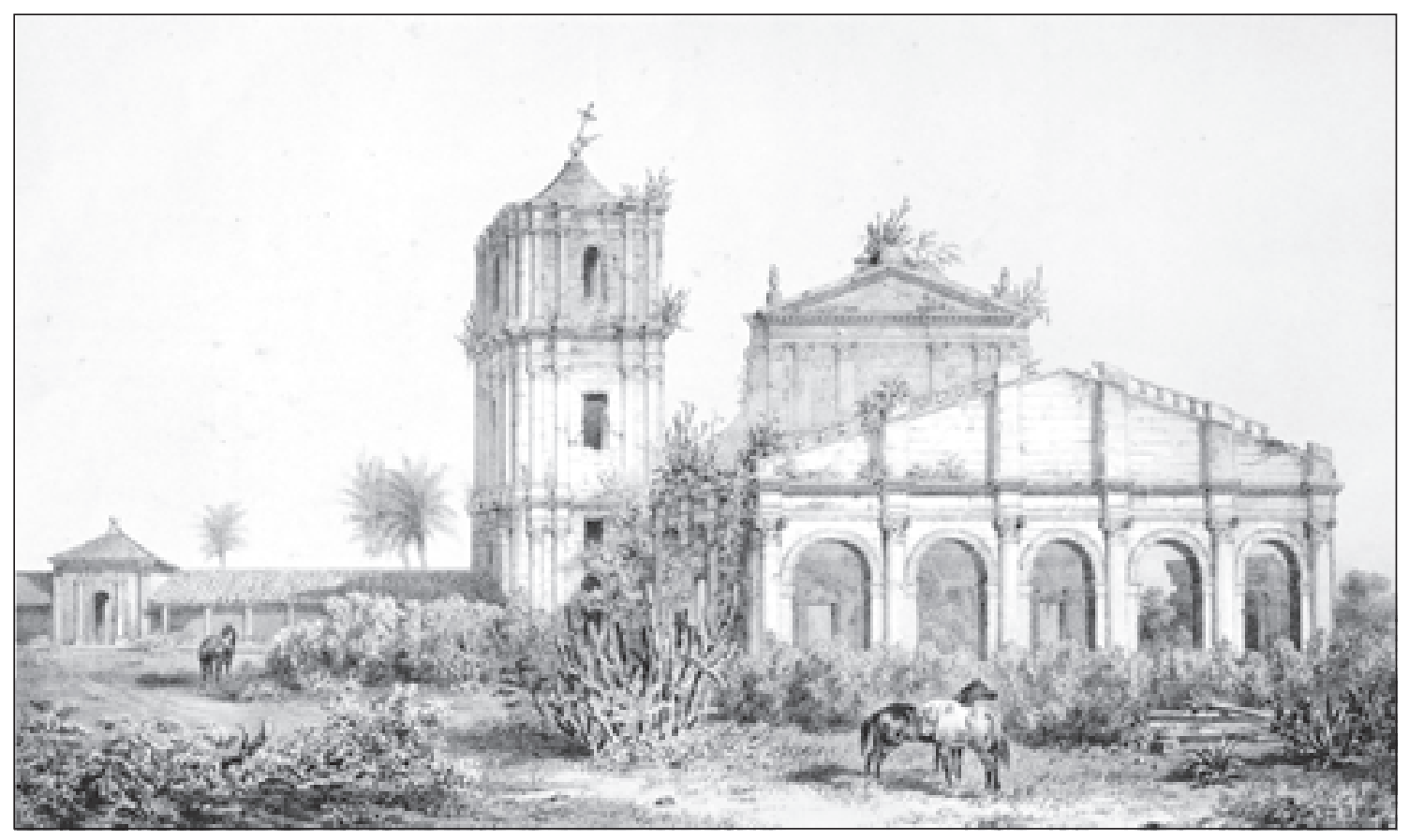

FIGURA 1 - Ruínas de São Miguel (ca. 1845), desenhada in loco por Alfred Demersay e publicada em seu livro de viagem.

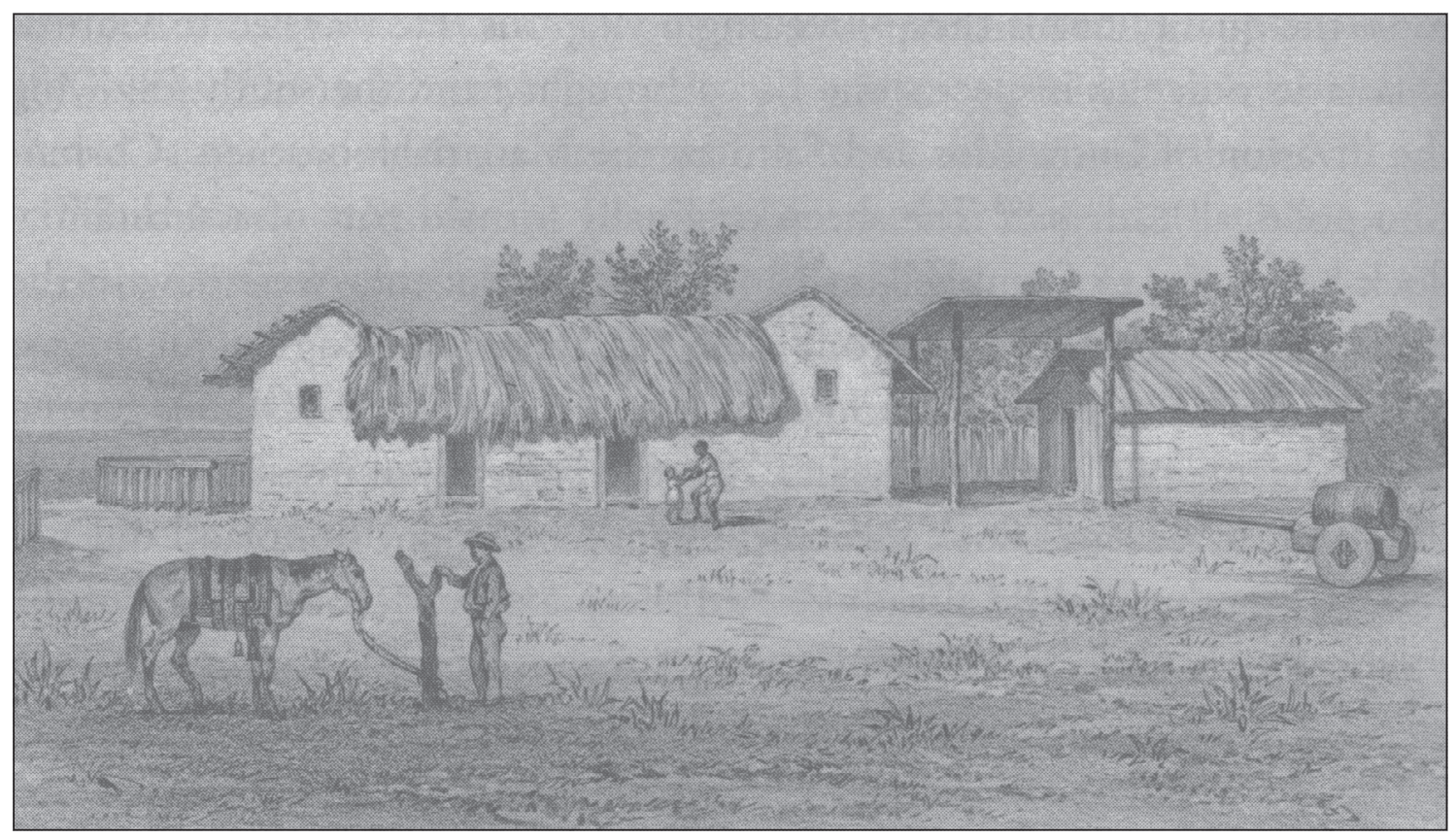

FIGURA 2 - Casa de Bonpland em São Borja (ca. 1845), desenhada in loco por Alfred Demersay e publicada em seu livro de viagem. 


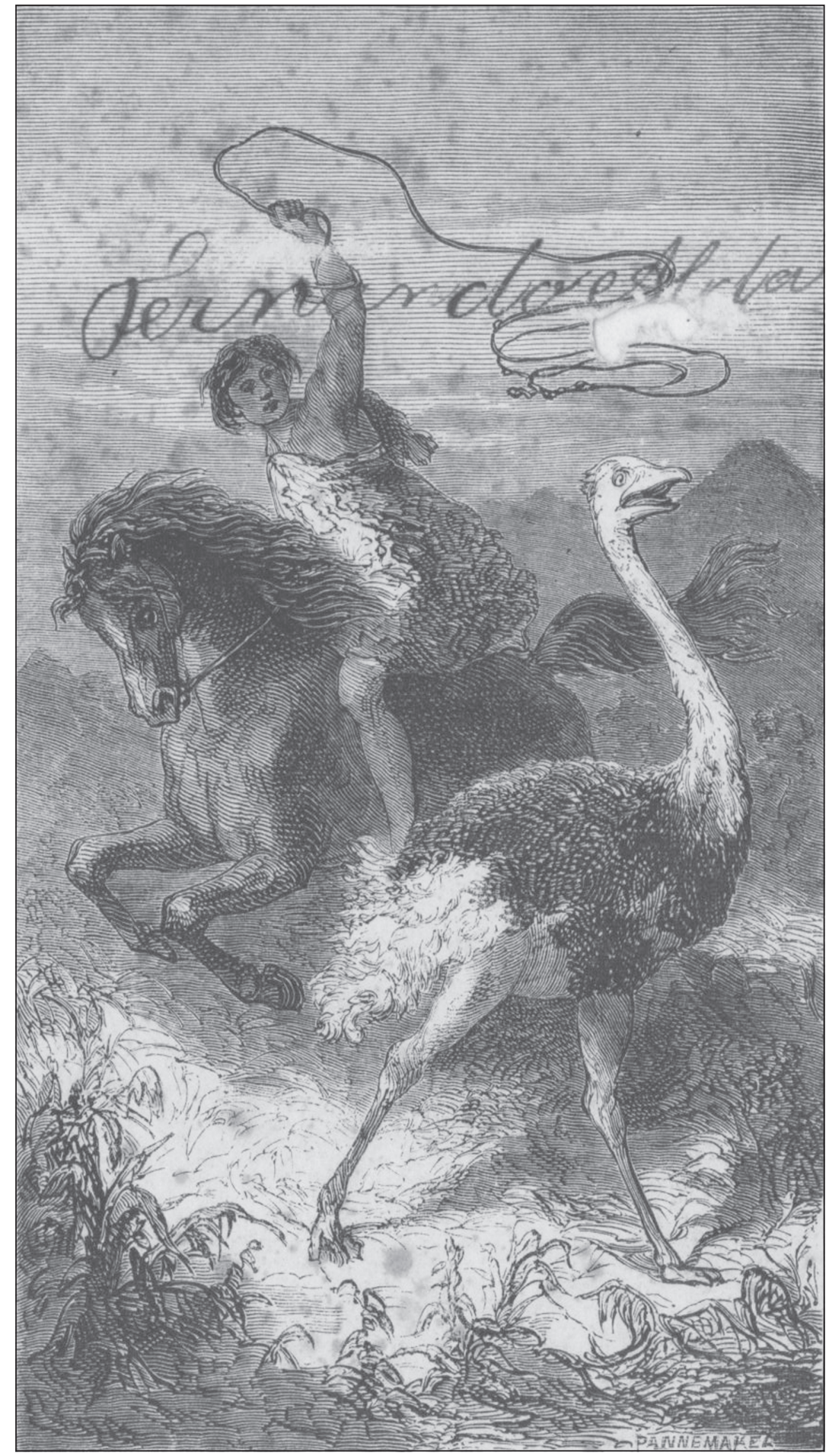

FIGURA 3 - Índio charrua a cavalo, caçando um ágil avestruz a laço, única ilustração constante na obra de Jean-JustÉtienne Roy. Trata-se, em verdade, de uma ema, Rhea americana (Linnaeus, 1758), a maior ave do continente americano (Família Rheidae). 
fundo, Roy relata, tão simplesmente, haver gasto quatro dias entre os mesmos pontos.

A referência ao "pampero", anteriormente apontada, bem como ao "terutero", nome castelhano da conhecida ave, saltam aos olhos do leitor como artefatos, utilizados com o único objetivo reforçar a (falsa) impressão de vivência pessoal.

Vale ressaltar que Roy repete, inclusive, um equívoco de Isabelle, ao informar que a igreja jesuítica de São Borja ficava na face norte da praça. Em verdade, ela ocupava o mesmo sítio da atual igreja matriz, no lado sul da praça, e isso sim - com sua fachada voltada para o norte. Sobre a planta da igreja, definida por ambos os autores como um "quadrado longo", a Figura 4 contesta a informação, pois mostra que ela era nitidamente retangular ${ }^{17}$, quase quatro vezes mais longa do que larga.

A respeito do "Arroyo del Tigre", primeiro pouso em terras brasileiras, cumpre informar que se trata, muito provavelmente, do afluente do rio Uruguai atualmente dito "Capão do Tigre", que tem sua foz a $30^{\circ} 01^{\prime} 21^{\prime \prime} \mathrm{S}$ e $57^{\circ} 21^{\prime}$ 34 "W, distando cerca de $30 \mathrm{~km}$ à montante da foz do rio Quaraí, em linha reta. ${ }^{18}$

Os textos do Quadro 1 comprovam, de forma definitiva, o caráter ficcional da obra de Roy, permitindo afirmar que ele não viajou pelo rio Uruguai, nunca esteve pessoalmente em São Borja e, também, não chegou a conhecer a notável personalidade científica que busca retratar em sua obra.

Ao contrário de Isabelle, Roy não faz maiores referências aos arredores da vila e, mesmo tendo ali permanecido por quinze dias, segundo suas palavras, nem menciona a propriedade rural de Bonpland, situada no rincão de São João

${ }^{17}$ Em vez de carré long, termo utilizado por Isabelle (quadrado longo, em português), mais adequado seria definir a planta da igreja jesuítica de São Borja como retangular (rectangulaire), de acordo com o "Plano da villa de São Francisco de Borja”, elaborado por Pedro Ferré (Figura 4).

${ }^{18}$ Informação fornecida pelo Prof. Enio Giotto (UFSM).
Mirim, próximo à foz do rio Piratini. Foi ali -e não na vila de São Borja - que Arsène Isabelle foi recebido pelo botânico francês, que "estava em vésperas de partir para a província de Corrientes, de onde deveria, em seguida, descer para Buenos Aires". ${ }^{19}$

A descrição da casa de Bonpland em São Borja, feita por Roy, mesmo afirmando ser "um rancho do mais simples aspecto" 20 , termos adequados à ilustração de Demersay (Figura 2), também não esconde claros indícios de suspeição, em suas escassas referências.

Sobre esse ponto, Stephen Bell manifesta estranheza pelas escassas referências ao "vasto jardim" que circundava a casa, plantado com "laranjeiras e árvores européias". ${ }^{21}$

A menção a um "tipo de alameda, fechada por um portão com grades" ${ }^{22}$, mostra-se luxo compatível a uma casa de campo da França, mas não ao rancho ilustrado por Demersay. Por sua vez, a "sebe de bromélias" que separava a propriedade de Bonpland das vizinhas, é informação recolhida, certamente, da obra de Isabelle, como demonstrado no Quadro 1. Cabe salientar, todavia, que esse detalhe refere-se às propriedades observadas entre o "passo" e a vila, mas não, especificamente, à casa de Bonpland em São Borja, posto que ao tempo da visita de Isabelle, o botânico vivia em sua propriedade rural. ${ }^{23}$

${ }^{19}$ ISABELLE, A. Viagem ao rio da Prata e ao Rio Grande do Sul. Rio de Janeiro: Livraria Editora Zelio Valverde S.A., 1949, p. 231.

${ }^{20}$ MARCHIORI NETO, D.L.; MARCHIORI, J.N.C. A viagem de Just-Jean-Étienne Roy (Armand de B***) ao oeste do Rio Grande do Sul. 1 - Visita a Aimé Bonpland na vila de São Borja. Balduinia, Santa Maria, n. 45, 2014, p. 23.

${ }^{21}$ BELL, S. A life in shadow. Aimé Bonpland in Southern South America, 1817-1858. Stanford: Stanford University Press, 2010. p. 158.

${ }^{22}$ MARCHIORI NETO \& MARCHIORI, 2014. Op. cit., p. 23.

23 "Passamos dois meses nas Missões, indo e vindo de São Borja ao Piratini, em cuja confluência estava o excelente Sr. Bonpland, vivendo isolado, instalado mais ou menos como o consolador de Chactas" (ISABELLE, 1949. Op. cit., p. 231). 
Cabe assinalar, entretanto, o acerto de Roy ao indicar o posicionamento da casa de Bonpland na "extremidade norte da vila" ${ }^{24}$, indicação confirmada pelo conde D’Eu, em sua "Viagem Militar ao Rio Grande do Sul". Na chegada a São Borja ${ }^{25}$, após a rendição das tropas paraguaias em Uruguaiana, a comitiva partiu para a vila "numa manhã fresca e radiosa":

Diante da primeira casa da vila apeia-se o Imperador para visitar um pequeno terreno rodeado de laranjeiras, hoje abandonado. Foi ali que durante 23 anos residiu o célebre naturalista Bonpland (...). Quanto à sua casa de São Borja, era uma "casa de capim", isto é, de taipa, coberta de palha, de modo que não tardou a cair e desaparecer. Restava a farmácia, situada na praça grande: queimaram-na este ano os paraguaios. ${ }^{26}$

Sete anos antes da visita imperial, foi Robert Avé-Lallemant ${ }^{27}$ que procurou Bonpland em São Borja, poucas semanas antes de sua morte. Hospedado na casa do "Vigário Gay"28, o mé-

${ }^{24}$ MARCHIORI NETO \& MARCHIORI, 2014. Op. cit., p. 23.

${ }^{25}$ O Imperador Dom Pedro II e sua comitiva chegaram ao passo de São Borja no dia 28 de setembro de 1865.

${ }^{26}$ CONDE D'EU, L.F.M.F.G. de O. Viagem militar ao Rio Grande do Sul. Belo Horizonte: Ed. Itatiaia; São Paulo: Ed. da Universidade de São Paulo, 1981. p. 114-115.

${ }^{27}$ Robert Christian Barthold Avé-Lallemant (Lübeck, 257-1812 - Lübeck, 10-10-1884), médico e explorador alemão, autor de diversas obras sobre o interior do Brasil, salientando-se a "Viagem pela Província do Rio Grande do Sul no ano de 1858".

${ }^{28}$ Natural dos Altos Alpes, na França (20-11-1815), JeanPierre Gay (1815-1891) era padre, escritor e amigo de Bonpland desde 1947, quando ele o conheceu em viagem a Alegrete, onde Gay era o responsável pelo curato. A amizade se consolidou quando o "Cônego Gay" tornou-se vigário de São Borja, posto por ele muito desejado, pela possibilidade de conviver com "uma notabilidade tão erudita e famosa" como Bonpland. Membro do Instituto Histórico e Geográfico Brasileiro, JeanPierre Gay deixou importante bibliografia, destacandose: História da República Jesuítica do Paraguay e Invasão paraguaia na fronteira brasileira do Uruguai. Em seus últimos anos, Gay foi pároco de Uruguaiana, cidade onde veio a falecer em 19 de maio de 1891 . dico e viajante alemão recebeu a notícia de que o "ancião estava gravemente doente" em sua estância de Santana, na província de Corrientes, motivo pelo qual apressou a partida para Uruguaiana, não sem antes visitar a "casa de Bonpland" na vila:

Estivemos em sua casa de campo e pomar. A casa tinha ainda o teto de palha, as singelas paredes de barro sustentadas por varas de bambu. A sala, ainda conservada, media exatamente 144 pés quadrados. Em uma parede colocara Bonpland sua farmácia, pois praticava a medicina em São Borja, como médico, da maneira mais desinteressada. Ao lado, o quarto de dormir, bem como a cozinha, laboratório, etc., os quais se desmoronaram. As suas cadeiras de madeira lavrada, simples, pintadas de verde-negro com listras amarelas, estavam ainda com o Vigário, em sua residência. Eu tinha três delas no meu quarto. Tão ermo e vazio como a casa do célebre botânico, estava seu pomar. Elevavam-se ainda acima das ervas belas laranjeiras, pessegueiros e roseiras; em toda a parte se reconhecia ainda a mão organizadora do hábil jardineiro: todavia o conjunto parecia um cemitério sem lápide, no qual as próprias plantas estavam de luto. Quis desiderio sit pudor aut modus tam chari capitis! ${ }^{29}$

$\mathrm{Na}$ casa nada mais havia, nem sequer as portas, mas só a abertura delas, de modo que em vão busquei uma lembrança. Bem perto da porta encontrei, no chão, uma guampa aparelhada com simplicidade, como usam os índios e habitantes do interior para tirar água e para guardar leite: exatamente o clássico chifre, com o qual eu já tomara leite algumas vezes. Foi essa a única vasilha que o velho deixou ficar no chão ao partir. Apanhei-a e levei-a comigo, em boa consciência, como querida e valiosa relíquia do lar de Bonpland em São Borja do Uruguai. ${ }^{30}$

${ }^{29}$ Expressão latina, de Horácio, que, em tradução livre, exclama: "Que recato ou medida pode definir os limites da saudade de tão querido amigo!".

${ }^{30}$ AVÉ-LALLEMANT, R. Viagem pela província do Rio Grande do Sul (1858). Belo Horizonte: Itatiaia, 1980. p. 269. 
Após a partida definitiva de Bonpland para a estância de Santana, na província de Corrientes, fato acontecido a primeiro de Junho de 1853, a sua casa de São Borja foi habitada a partir do primeiro semestre de 1855 pela família de Manuel Luis Osório ${ }^{31}$, o futuro marquês do Herval, durante o período de sua nomeação como comandante da "fronteira de São Borja". Em 1858, de acordo com Avé-Lallemant, a casa já estava abandonada e quase em ruínas, permitindo concluir que a guampa levada como souvenir pelo viajante alemão, pertencera, mais provavelmente, à família do militar brasileiro.

A situação geográfica da casa e quinta de "Bonplan" na "villa de São Francisco de Borja" fica definitivamente esclarecida ao se examinar um mapa ${ }^{32}$ de junho de 1845 , integrante do acervo do Arquivo Histórico da cidade (Figura 4): ela situava-se, em verdade, a noroeste da praça da antiga redução jesuítica, a qual ainda estava delimitada, na época, pelas "casas del pueblo" em suas faces leste, oeste e norte, constando a "Iglesia vieja" e o "Collegio" em seu lado sul. A grande seta, mostrada parcialmente no fragmento reproduzido, indica o Norte geográfico.

A respeito de sua localização na atual malha urbana da cidade, pode-se afirmar que a rua Aimé Bonpland cruza pelo terreno outrora pertencente ao botânico francês, e que o "Museu da Estância" do grupo "Os Angüeras" encontra-se muito perto, senão no próprio local da extinta casa ilustrada por Alfred Demersay.

Cumpre notar, ainda, que a planta da casa de Bonpland fazia ângulo reto com a direção geral

${ }^{31}$ BELL, 2010. Op. cit., p. 201.

${ }^{32} \mathrm{O}$ autor agradece ao Prof. Muriel Pinto (UNIPAMPA, São Borja) pelo acesso ao mapa de Ferré. A longa, produtiva e agradável conversa mantida com os professores Muriel Pinto e Edson Paniagua na noite de 8 de Julho de 2014, além de ajudar a esquecer, por completo, o fatídico jogo da Copa do Mundo, terminado poucas horas antes, estabeleceu uma amizade que haverá de se manifestar em trabalhos conjuntos no futuro. A eles, e a Clóvis Benevenuto, do Arquivo Histórico de São Borja, os mais sinceros agradecimentos do autor pela generosa acolhida. da trilha que unia o "passo de São Borja" à vila, tendo a frente voltada para o Norte ou para o $\mathrm{Sul}^{33}$. O mapa de 1845 indica, ainda, a existência de outras quatro casas, em quadrículas situadas ao Norte da casa de Bonpland. ${ }^{34}$

A respeito desse mapa, que por sua carga informativa demanda análise em artigo à parte, pode-se adiantar que se trata de obra de Pedro Ferré, e que foi elaborado "a pedido da Câmara Municipal". O paradeiro do documento original resta à espera de investigação, posto que o material examinado é uma cópia realizada em "Julho de 1898", "por ordem do Intendente do município, Sr. Coronel Julio Garcia Trois". ${ }^{35}$

Sobre o autor do mapa, cabe salientar seu papel destacado na história argentina do século dezenove, e que ele vivia exilado em São Borja, na época, por questões políticas. Amigo de Bonpland, desde sua libertação do cativeiro no Paraguai, Pedro Ferré foi governador da província de Corrientes por três vezes, e um dos constituintes responsáveis pela Carta Magna da Argentina de 1853. Foi nessa vila brasileira, ainda, que Pedro Ferré escreveu as suas "Memórias", importante obra literária para a História, bem como para o conhecimento da vida social e costumes do vizinho país no século dezenove.

Outro ponto a destacar é que o mapa de Ferré é contemporâneo ao desenho da "casa de Bonpland", publicado por Alfred Demersay.

Embora pequena e situada nos confins do Império, a vila de São Borja abrigava ao final da primeira metade do século dezenove uma variada comunidade de cultos estrangeiros, salientando-se, além de Bonpland e Pedro Ferré, o francês José Ingres, irmão do famoso pintor Jean-Auguste-Dominique Ingres (1780-1867).

\footnotetext{
${ }^{33}$ Provavelmente para o Norte, lado favorecido pela luz solar.

${ }^{34}$ Para maior legibilidade das informações, optou-se por reproduzir parcialmente o mapa de Ferré, excluindo essas quatro casas, bem como a escala, "em varas castellanas", e a legenda, escrita em belíssima caligrafia.

${ }^{35}$ Informações extraídas da legenda do mapa.
} 


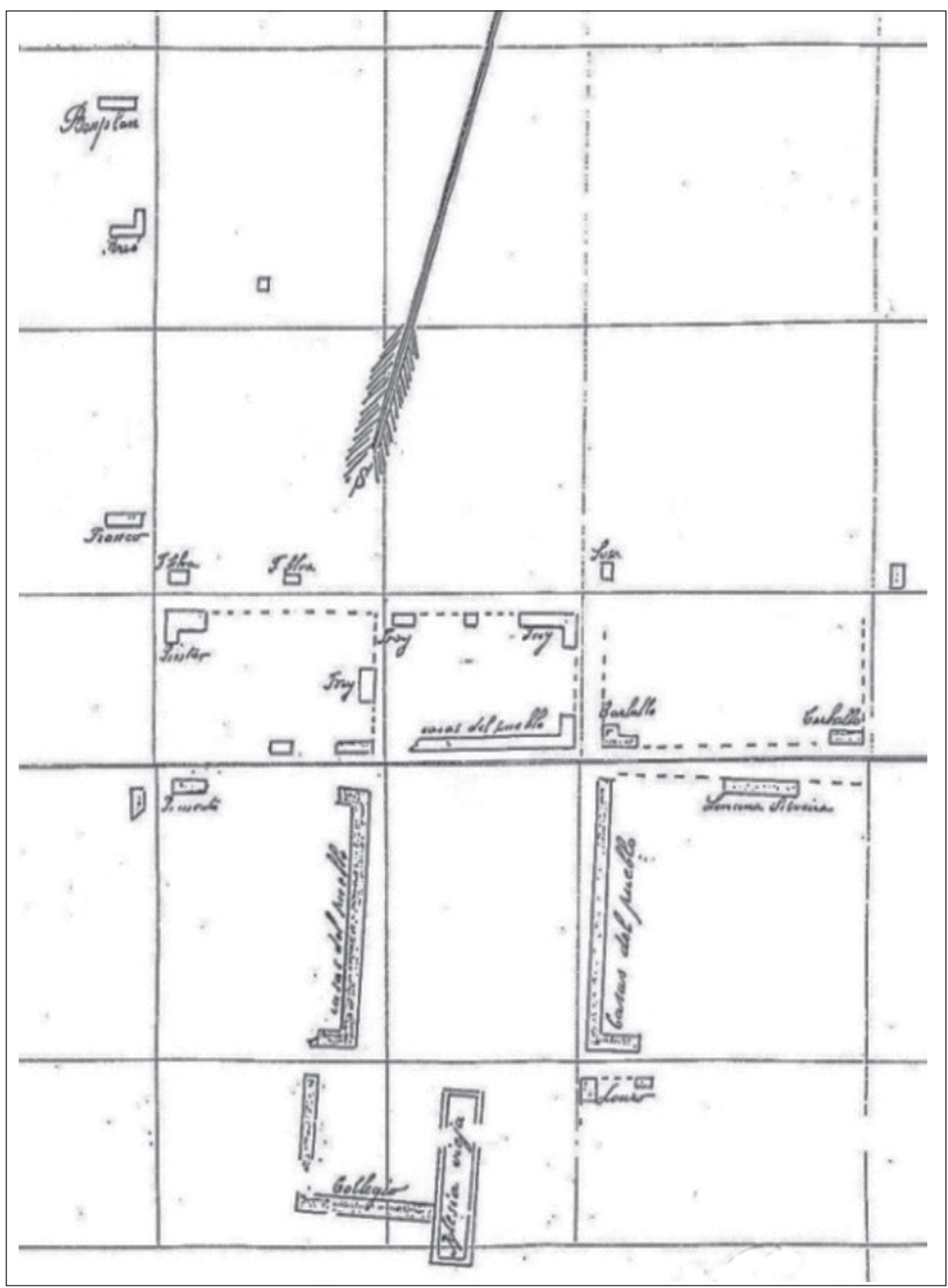

FIGURA 4 - Mapa da vila de São Francisco de Borja, levantado por Pedro Ferré a pedido da Câmara Municipal, em Junho de 1845. Reproduzido de cópia providenciada por ordem do Intendente do município, Sr. Coronel Julio Garcia Trois, em Julho de 1898 (Arquivo Histórico de São Borja). 
A partir de 1947, após uma visita de Bonpland a Alegrete, outro eminente francês que tratou de se transferir para São Borja foi o Cônego Gay, com vistas, sobretudo, à possibilidade de conviver com "uma notabilidade tão erudita e famosa" ${ }^{36}$, como esse velho parceiro de Alexander von Humboldt na "Voyage aux régions équinoxiales du Nouveau Continent".

Para o Padre Gay, todavia, essa convivência durou poucos anos, visto que Bonpland deixou São Borja para morar em sua estância de Corrientes no dia 01 de Junho de 1853, como visto anteriormente. Pouco depois da partida, o botânico francês aceitava, por carta de 5-9-1853, o convite do Padre Gay para integrar a loja maçônica de rito escocês "Augusta Cordialidade no Oriente", de São Borja ${ }^{37}$; a iniciação como membro pleno, todavia, deu-se apenas durante sua última visita à vila, em 1856 - e por insistência do Cônego Gay -, que lhe cobrava a urgência de comparecer a uma das sessões regulares dos sábados ${ }^{38}$.

Muitos foram os viajantes que enfrentaram longas distâncias, em precários meios de transporte, com o objetivo de se encontrar com Aimé Bonpland, o último dos quais, provavelmente, foi Avé-Lallemant. Com o presente artigo, fica comprovado que Just-Jean-Étienne Roy, apesar de haver escrito um livro sobre o tema, não merece inclusão nessa lista.

Por fim, a respeito do plágio presentemente demonstrado, resta acrescentar que essa prática não era tão incomum em obras do século dezenove, nem recebia, na época, a censura que hoje merece. Em tempos de escassa informação e de grande curiosidade popular sobre terras e povos distantes, esse tipo de literatura servia, ao menos, para preencher uma lacuna edi-

${ }^{36}$ BELL, 2010. Op. cit., p. 162.

${ }^{37}$ CORDIER, H. Papiers inédites du naturaliste Aimé Bonpland conservés a Buenos-Aires. Comptes-rendus des séances de l'Academie des Inscriptions et BellesLettres, v. 54, n. 6, p. 456, 1910.

${ }^{38}$ BELL, 2010. Op. cit., p. 184-185. torial e, neste aspecto, chegou a lograr sucesso. ${ }^{39}$

\section{REFERÊNCIAS BIBLIOGRÁFICAS}

AVÉ-LALLEMANT, R. Viagem pela província do Rio Grande do Sul (1858). Belo Horizonte: Itatiaia, 1980. $417 \mathrm{p}$.

B***, A. de. Mes voyages avec le Docteur Philips dans les républiques de La Plata (Buenos-Ayres, Montevideo La Banda-Oriental etc). Tours: Alfred Mame et fils, 1876. 192 p.

BARRETO, A. Bibliografia sul-riograndense. Rio de Janeiro: Conselho Federal de Cultura, 1976. v. 2. p. 737-1.556.

BELL, S. A life in shadow. Aimé Bonpland in Southern South America, 1817-1858. Stanford: Stanford, University Press, 2010. 320 p.

CONDE D'EU, L.F.M.F.G. de O. Viagem militar ao Rio Grande do Sul. Belo Horizonte: Ed. Itatiaia; São Paulo: Ed. da Universidade de São Paulo, 1981. 186p.

CORDIER, H. Papiers inédites du naturaliste Aimé Bonpland conservés a Buenos-Aires. Comptesrendus des séances de l'Academie des Inscriptions et Belles-Lettres, v. 54, n. 6, p. 456, 1910.

DEMERSAY, A. Notice sur la vie et les travaux de M. Aimé Bonpland. Bulletin de la Societé de Géographie, Paris, v. 5, p. 240-254, 1853.

DEMERSAY, A. Histoire physique, économique et politique du Paraguay et des établissements des jésuites. Paris: L. Hachette et Cie., 1860-1865. (2 volumes).

FORTES, A.B.; WAGNER, J.B.S. História administrativa, judiciária e eclesiástica do Rio Grande do Sul. Porto Alegre: Editora Globo, 1963. $497 \mathrm{p}$.

ISABELLE, A. Viagem ao Rio da Prata e ao Rio Grande do Sul. Rio de Janeiro: Livraria Editora Zelio Valverde S.A., 1949. 345 p.

\footnotetext{
${ }^{39}$ São conhecidas quatro edições da obra, pelo menos, a primeira das quais data de 1860 .
} 
MARCHIORI NETO, D.L.; MARCHIORI, J.N.C. A viagem de Just-Jean-Étienne Roy (Armand de $\left.\mathrm{B}^{* * *}\right)$ ao oeste do Rio Grande do Sul. 1 - Visita a Aimé Bonpland na vila de São Borja. Balduinia, Santa Maria, n. 45, p. 17-32, 2014. MARTINS, A. Escritores do Rio Grande do Sul.
Porto Alegre: Ed. da Universidade Federal do Rio Grande do Sul; Instituto Estadual do Livro, 1978. $640 \mathrm{p}$.

VILLAS-BÔAS, P. Notas de bibliografia sul-riograndense: autores. Porto Alegre: A Nação; Instituto Estadual do livro, 1974. 620 p. 
